\title{
PEDAGOGIAS CULTURAIS NA REVISTA TODATEEN: PRODUZINDO MODOS DE SER FEMININA
}

\author{
Saionara Vitória de Almeida ${ }^{1}$ \\ Raquel Quadrado ${ }^{2}$
}

\begin{abstract}
Resumo: Este trabalho tem por objetivo problematizar uma seção de uma revista disponibilizada na WEB, que se destina ao público adolescente feminino (dos doze aos dezenove anos) - a Revista Todateen , mais especificamente a sessão "Toda Diva". A proposta é a de mostrar as questões apresentadas pela revista voltadas a ensinar procedimentos para diversos fins e a linguagem usada nessas informações que têm o público adolescente como leitores. Muito mais do que seduzir a consumidora ou induzi-la a obter determinado produto, a publicidade que ali se apresenta comporta um tipo de pedagogia e de currículo culturais. Estes, entre outras coisas, produzem valores e saberes; regulam condutas e modos de ser; re-produzem identidades e representações; constituem certas relações de poder e ensinam modos de ser mulher e de ser homem, formas de feminilidade e de masculinidade.
\end{abstract}

Palavras-chave: Feminilidade, Pedagogia, Publicidade.

\section{CULTURAL PEDAGOGIES IN THE MAGAZINE TODATEEN: PRODUCING MODES OF BEING FEMININE}

\begin{abstract}
This work has the objective of problematizing a section of a magazine made available on the WEB, which is intended for the female teen audience (aged twelve to nineteen) - Todateen Magazine, more specifically the "Toda Diva" session. The proposal is to show the questions presented by the magazine aimed at teaching procedures for various purposes and the language used in this information that have the adolescent audience as readers. Much more than seducing the consumer or inducing her to obtain a particular product, the advertising presented here entails a type of cultural pedagogy and curriculum. These, among other things, produce values and knowledge; Regulate behaviors and ways of being; Re-produce identities and representations; Constitute certain relations of power and teach ways of being a woman and being a man, forms of femininity and masculinity.

Keywords: Femininity, Pedagogy, Advertising.
\end{abstract}

\footnotetext{
1 Possui graduação em Letras - Português e Inglês pela Universidade Federal do Rio Grande (1987). Atualmente é professora da Prefeitura Municipal de Rio Grande. Tem experiência na área de Educação, com ênfase em formação docente. Fez especialização em Tecnologias da Informação e da Comunicação na Educação pela Universidade Federal do Rio Grande- FURG. Mestranda do Programa de Pós-graduação em Educação pela Universidade Federal do Rio Grande- FURG, sob orientação da Profa. Dra. Raquel Quadrado.

2 Possui Graduação em Licenciatura em Ciências - Habilitação Biologia pela Universidade Federal do Rio Grande - FURG, Mestrado em Educação Ambiental pela FURG e Doutorado em Educação em Ciências pela Universidade Federal do Rio Grande - FURG. Em 2016 realizou Pós-doutorado na Escola Superior de Educação do Instituto Politécnico de Coimbra (Portugal), com a orientação da Professora Doutora Maria Filomena Rodrigues Teixeira. Atualmente é professora Adjunta do Instituto de Educação da Universidade Federal do Rio Grande - FURG, professora do Programa de Pós-Graduação em Educação em Ciências (Associação Ampla FURG/UFRGS/UFSM) e do Programa de Pós-Graduação em Educação da FURG. Atua como pesquisadora no Grupo de Pesquisa Sexualidade e Escola (GESE). Tem experiência na área de Educação, Educação para a Sexualidade e Educação em Ciências, com ênfase na formação inicial e continuada de professores.
} 


\section{Introdução}

Este trabalho tem por objetivo problematizar uma seção de uma revista disponibilizada na WEB, que se destina ao público adolescente feminino (dos doze aos dezenove anos) - a Revista Todateen (Editora Alto Astral) ${ }^{3}$ na sua seção que se intitula “Toda Diva”. A proposta é a de mostrar as questões apresentadas pela revista voltadas a ensinar procedimentos para diversos fins assim como a linguagem usada nessas informações que têm o público adolescente como leitores. Muito mais do que seduzir a consumidora ou induzi-la a obter determinado produto, a publicidade que ali se apresenta comporta um tipo de pedagogia e de currículo culturais. Estes, entre outras coisas, produzem valores e saberes; regulam condutas e modos de ser; re-produzem identidades e representações; constituem certas relações de poder e ensinam modos de ser mulher e de ser homem, formas de feminilidade e de masculinidade.

Primeiro um pouco de história para situar esse trabalho no campo dos Estudos Culturais que se originou na Inglaterra, no Centro de Birmingham, na segunda metade do século XX, em que as relações entre a cultura contemporânea e a sociedade, suas formas culturais, instituições e práticas culturais, assim como suas relações com a sociedade e as mudanças sociais. Nesse estudo cabe salientar a pesquisa realizada por Richard Hoggart, com o texto The uses of literacy (1957) através da metodologia qualitativa, em que seu foco de atenção são os materiais culturais antes desprezados, da cultura popular e dos mass media. Inaugura assim a perspectiva que argumenta que no âmbito popular existe resistência e não apenas submissão. Ainda como bases do surgimento dos Estudos Culturais menciona-se Raymond Williams com Culture and society (1958) e E.P. Thompson com The making of de english working-class (1963).

Os Estudos Culturais não constituem um conjunto articulado de idéias e pensamento. Como dizem seus cronistas mais contundentes, eles são e sempre foram um conjunto de formações instáveis e descentradas. Há tantos itinerários de pesquisa e tão diferentes posições teóricas que eles poderiam ser descritos como um tumulto teórico. (COSTA, SILVEIRA \& SOMMER, 2003, p.39)

Os Estudos Culturais compreendem os produtos culturais como agentes de reprodução social, fortalecendo a sua natureza complexa, dinâmica e ativa na construção da hegemonia. Não existe um confronto bipolar e rígido entre as diferentes culturas, mas sim um jogo de intercâmbios entre elas, não são exteriores entre si, mas comportando

\footnotetext{
${ }^{3}$ EDITORA ALTO ASTRAL. Publicidade. [online]. Disponível na Internet via WWW. URL: http://loja.editoraastral.com.br/categoria/teen Arquivo capturado em: 28 de março de 2016.
} 
intersecções, transações e cruzamentos. Por horas a cultura popular resiste e impugna a cultura hegemônica; por hora reproduz a concepção de mundo e de vida das classes hegemônicas.

Saberes nômades, que migram de uma disciplina para outra, de uma cultura para outra, que percorrem países, grupos, práticas, tradições, e que não são capturados pelas cartografias consagradas que têm ordenado a produção do pensamento humano - eis uma descrição que parece provisoriamente adequada para me referir ao ethos contingente do que tem sido denominado e estudos Culturais, ou Cultural Studies, em sua versão contemporânea. (COSTA, 2004, p.13)

O campo dos Estudos Culturais tem sido um espaço intelectual dedicado a examinar os novos lugares de produção de sujeitos, assim sendo o controvertido conceito de pedagogias culturais uma das ferramentas teóricas de grande utilidade. Para se chegar ao conceito de Pedagogia Cultural com os usos que se têm nos dias de hoje, muitas discussões sobre pedagogia e suas relações com a cultura foram e ainda continuam sendo necessárias.

\section{A pedagogia cultural}

No contexto dos Estudos Culturais emerge o conceito de pedagogia cultural que se opera nas sociedades desse mundo globalizado em que pedagogias são praticadas por programas televisivos, jornais, revistas, filmes, peças publicitárias, sites e uma variedade muito grande de outros artefatos que atravessam a vida contemporânea. Hoje estão implicados uma variedade grande de espaços e de artefatos culturais nas formas que as pessoas pensam e agem sobre si mesmas e sobre o mundo que as cerca, assim como nas escolhas que fazem e nas formas que organizam as suas vidas.

Em um trabalho de pesquisa que trata da articulação dos Estudos Culturais com a escola: uma possibilidade há uma explicação que diz:

Finalmente, em nosso percurso pelas movimentações dos EC e por seus cruzamentos com a educação e a pedagogia, encontramos subsídios para afirmar que a educação se dá em diferentes espaços do mundo contemporâneo, sendo a escola apenas um deles. Quer dizer, somos também educados por imagens, filmes, textos escritos, pela propaganda, pelas charges, pelos jornais e pela televisão, seja onde for que estes artefatos se exponham. Particulares visões de mundo, de gênero, de sexualidade, de cidadania entram em nossas vidas diariamente. É a isto que nos referimos quando usamos as expressões currículo cultural e pedagogia da mídia. (COSTA, et al., 2003, p. 57)

Hoje se fala em pedagogia da mídia, pedagogia escolar, pedagogia do consumo, 
pedagogia radical, pedagogia do corpo, entre outros. Será que o sucesso de cada uma dessas pedagogias que produzimos e multiplicamos estão diretamente relacionadas aos usos que as damos na vida diária, atuando de toda forma sobre nós mesmos, produzindo sujeitos conectados ao tempo em questão? Tem se percebido, como diz Camozzato (2015) que em cada seara da vida e em cada campo do saber há investimentos preciosos, minuciosos, bem planejados e repletos de intencionalidade. Todos, na verdade, atuando sobre as pessoas, como pedagogias para ensinar saberes e práticas necessárias aos constantes ajustes para as condições desse tempo espaço preciso.

Em tempos de um modo de viver cambiante, provisório, as pedagogias que entendam as dinâmicas que hoje sustentam as diferentes construções das subjetividades são cada vez mais exigidas. Tem que oferecer pedagogias atraentes aos sujeitos desse tempo presente, ajustar o olhar para compreender as transformações do tempo, abrir-se e ajustarse a novas discussões que esse movimento oportunizará ao campo educacional e às novas pesquisas.

Nos estudos realizados por pesquisadores, nas seções sobre Pedagogias Culturais evidenciam-se que os artefatos de comunicação educam, regulam condutas, subjetivam. Como diz Sodré (2003), as pedagogias de hoje ensinam “comportamentos, hábitos, valores e procedimentos considerados adequados utilizando-se, para tanto, de diferentes artefatos culturais como o cinema, a televisão, as revistas, a literatura, a moda, a publicidade, a música” (p.15).

Autores brasileiros assim como autores internacionais enfocam de formas ora mais culturalistas, ora mais foucaultianas da produtividade dos artefatos da mídia na construção de representações e de modos de ser, subsidiando as pesquisas sobre os modos como as pedagogias culturais operam. $\mathrm{O}$ conceito de pedagogia cultural à medida do conjunto de trabalhos que se apresenta é ferramenta teórica central, dessa forma os pesquisadores conseguem mostrar não somente os efeitos de tais pedagogias, mas também os modos como eles são produzidos.

Nesse trabalho, por se tratar da análise de uma seção de uma revista disponibilizada na WEB, quer-se ver a pedagogia que se opera nessa mídia.

Pedagogia da mídia refere-se à prática cultural que vem sendo problematizada para ressaltar essa dimensão formativa dos artefatos de comunicação e informação na vida contemporânea, com efeitos na política cultural que ultrapassam e/ou produzem as barreiras de classe, gênero sexual, modo de vida, etnia e tantas outras. (COSTA, et al., 2003, p.57) 
A pedagogia, conforme Larrosa (1994), por seu caráter constitutivo, tem sido uma das tecnologias mais produtivas na regulação de sujeitos. Entendida como uma prática cultural em que os objetivos voltam-se para a modificação dos modos de ser sujeito, não pode ser considerada como um espaço neutro ou de simples mediação. A pedagogia é um espaço de construção e atua "produzindo formas de experiência de si nas quais os indivíduos podem se tornar sujeitos de um modo particular" (p.57). E Larrosa (1994) ainda diz que as instâncias pedagógicas que fazem com que os sujeitos incidam sobre si mesmos atuam como dispositivos pedagógicos e "um dispositivo pedagógico será, então, qualquer lugar no qual se constitui ou se transforma a experiência de si. Qualquer lugar no qual se aprendem ou se modificam as relações que o sujeito estabelece consigo mesmo" (id.ib.)

Assim, com esse panorama o presente trabalho mostra que as pedagogias são praticadas em distintos espaços e contextos, baseadas numa concepção de educação com a intenção de moldar e de dirigir condutas, implicando tanto na forma como as pessoas pensam e agem sobre si mesmas e sobre o mundo que as cerca, assim como nas escolhas que realizam e nas maneiras que organizam as suas vidas.

\begin{abstract}
É importante explicitar que, apoiadas nos Estudos Culturais, que defendem que existe pedagogia, modos de ensinar e possibilidades de aprender nos mais diferentes artefatos culturais, que se multiplicaram na nossa sociedade, ampliamos nossos objetos curriculares, para investigar todo e qualquer artefato cultural que ensina, buscando mostrar o currículo que eles apresentam. Claro, para isso tivemos que ampliar nosso vocabulário teórico-metodológico, porque foi necessário inventar procedimentos que possibilitassem "ler" esses diferentes artefatos e estabelecer relações com a educação escolar. (MEYER \& PARAÍSO, 2012, p.24)
\end{abstract}

\title{
Revista Todateen virtual - um artefato poderoso na pedagogia contemporânea
}

As revistas em geral trazem quantidade de informações e atualidades para suprir de informações o público a que se destinam. Sendo assim, o trabalho em questão tem como foco a seção "Toda Diva" da Revista Todateen ${ }^{4}$, que envolve o público adolescente feminino - dos doze aos dezenove anos - em uma quantidade variada de informações, sugerindo modos de ser e de agir diante de inusitadas situações que compreendem a rotina de adolescentes, operando através de seus conceitos, dicas de como ser ou fazer isto ou

\footnotetext{
${ }^{4}$ REVISTA TODATEEN - no site você pode alterar a forma como a revista aparece na parte que diz "TTcom seu estilo" além de navegar por vários assuntos ligados aos temas adolescentes, entre eles o que esse trabalho se direciona que é a seção Toda Diva. Disponível via WWW. URL: http://todateen.uol.com.br Arquivo capturado em: 28 de março de 2016.
} 
aquilo, ensinamentos, a vida de celebridades, a moda que impera no momento, numa forma de manual de ser e de fazer produzindo subjetividades.

Com uma página na internet colorida e atrativa, a revista em questão se apresenta para o público com um verdadeiro cardápio de seções (Fig. 1) para o internauta navegar e tirar o máximo de proveito das dicas e informações que nela contém. As seções como Teen Week, Toda Diva, Papo de BFF (Best Friend Forever), Gatos, Blogs, Testes, Promoções, Fun, Astral e Você na TV são de direto acesso e cada uma dessas seções apresenta itens de variados temas para que o seu público-alvo interaja lendo, aprendendo, fazendo uso para si do que julgou ser útil para aquele momento.

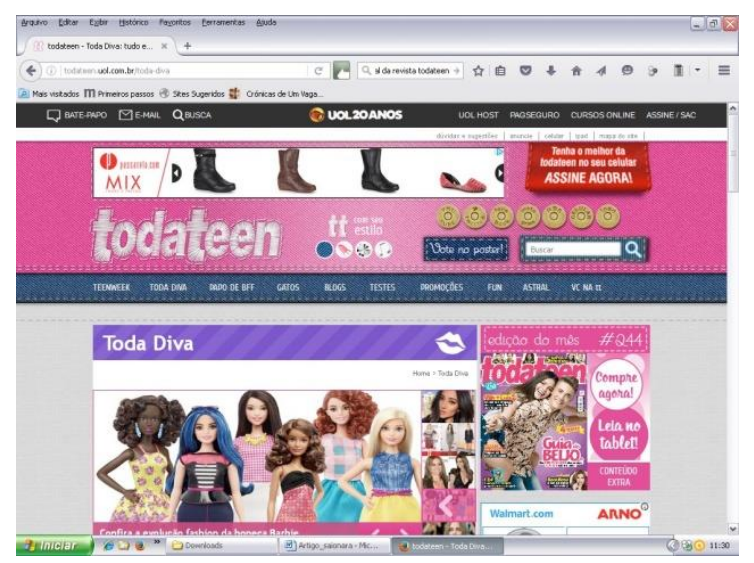

Figura 1 - Página da Revista Todateen onde aparecem todas as seções para clicar. Fonte: Página da Revista Todateen na $\mathrm{WEB}^{5}$.

Em apenas um click, adolescentes são levadas a pesquisar sobre os mais variados temas referentes à beleza e a todo tipo de formas de condutas, com ensinamentos, passo-apasso de como alcançar isso ou aquilo, com dicas intermináveis de usos de produtos assim como o incentivo em adquiri-los.

A parte da revista que se intitula "Toda Diva" oferece divisões que tratam de diferentes aspectos para a adolescente se tornar uma diva por inteiro. A seguir as divisões e um pouco sobre cada uma delas:

a) It girl (Fig. 2) - nessa parte da revista, várias celebridades são apresentadas, com seus estilos de ser e de vestir para que as leitoras possam adotar os looks dessas celebridades e conheçam como essas celebridades se destacam no mundo fashion. Fotos de roupas, cabelos, registros de antes e depois do sucesso das celebridades, dicas de acessórios usados por elas, o quanto custa ser como essas celebridades à medida que falam dos produtos que usam e o quanto custam.

\footnotetext{
${ }^{5}$ Disponível em http://todateen.uol.com.br/toda-diva> acesso em: março de 2016.
} 


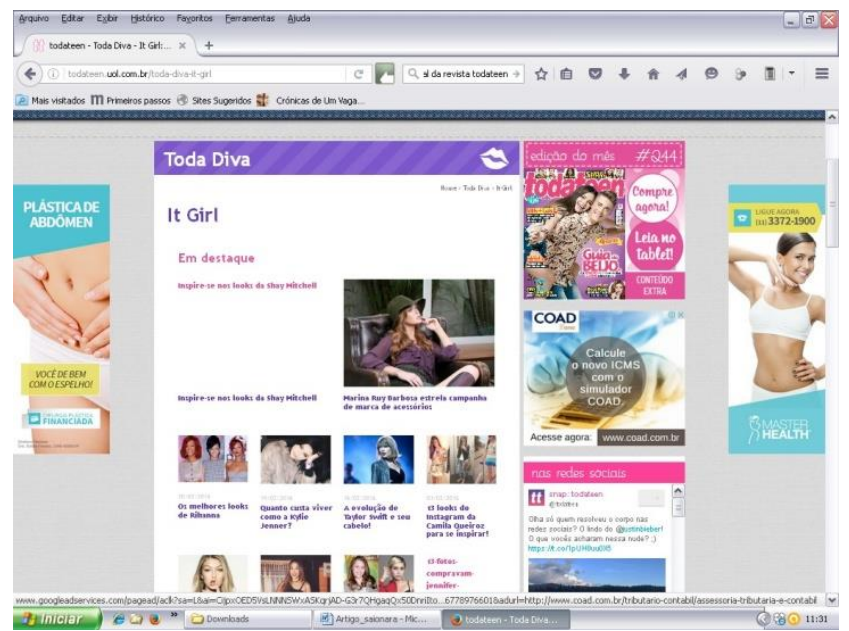

Figura 2 - A seção Toda Diva e uma das suas divisões "It Girl” da Revista Todateen. Fonte: Página da Revista Todateen na $\mathrm{WEB}^{6}$.

b) Batalha de looks (Fig. 3) - nessa parte as leitoras enviam fotos de seus looks para serem apreciados e votados. O look que tiver mais votos aparecerá na próxima edição da revista. Nessa seção ensina como participar e mostra o regulamento. "Quer aparecer na próxima edição da revista? Envie uma foto do seu look preferido" - dessa forma a revista faz um convite para as suas leitoras agregarem a ideia de aparecer na revista.

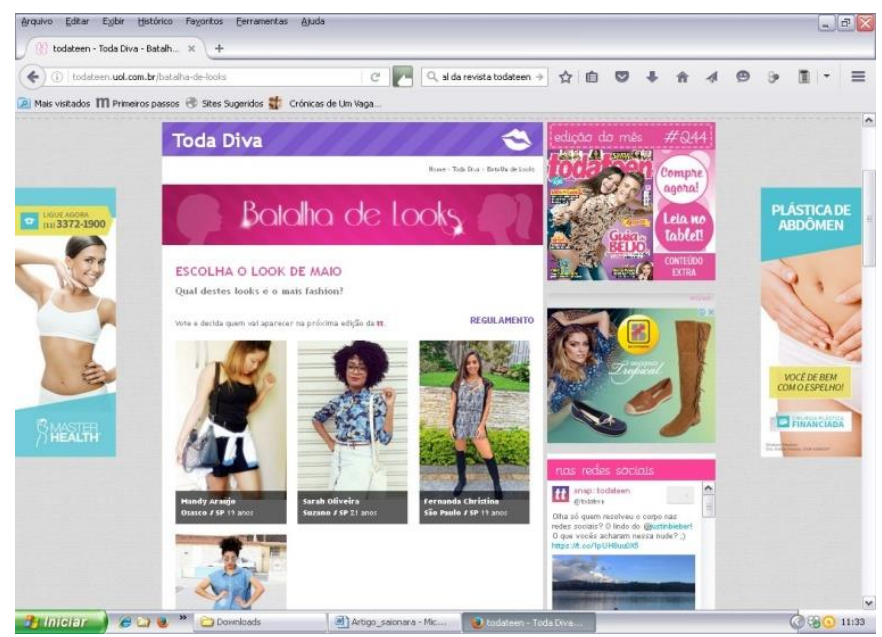

Figura 3 - A seção Toda Diva e uma das suas divisões "Batalha dos Looks" da Revista Fonte: Página da Revista Todateen na $\mathrm{WEB}^{7}$.

c) Beleza (Fig. 4) - todo o tipo de conselho ou dica é apresentado aqui nessa seção para que as leitoras aprendam sobre como ficar bonita conforme sugere a revista, com abordagens em destaque seja quanto a cabelo, corpo, dietas, modos, posturas e mostrando exemplos de modelos de como fazer com as celebridades.

\footnotetext{
${ }^{6}$ Disponível em http://todateen.uol.com.br/toda-diva-it-girl> acesso em: março de 2016.

${ }^{7}$ Disponível em http://todateen.uol.com.br/batalha-de-looks $>$ acesso em: março de 2016.
} 


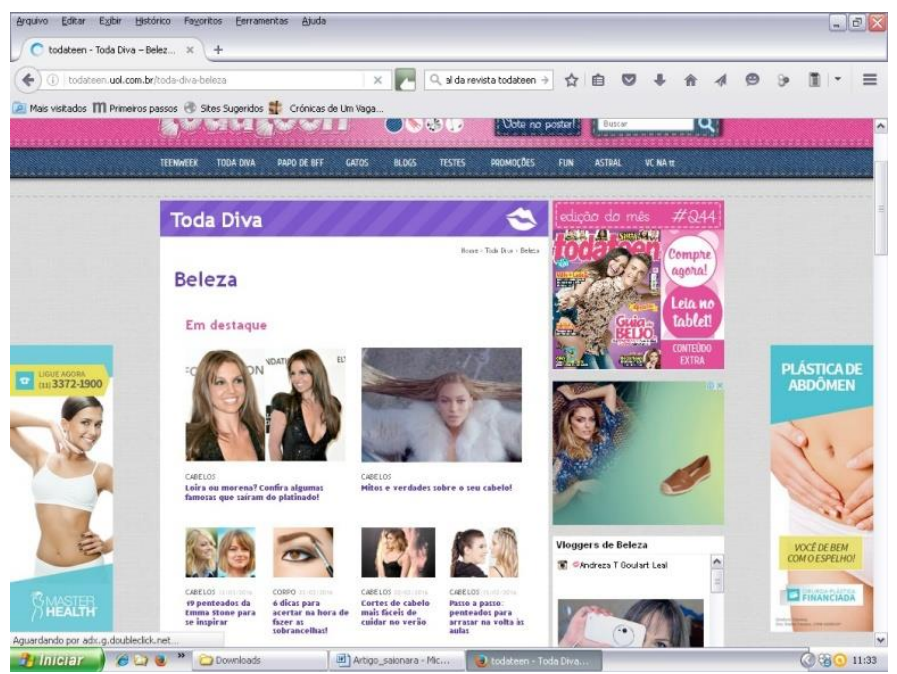

Figura 4 - A seção Toda Diva e uma das suas divisões "Beleza” da Revista Todateen Fonte: Página da Revista Todateen na $\mathrm{WEB}^{8}$.

d) Moda (Fig. 5) - um completo guia de como ser e como aparecer em qualquer lugar. Como se vestir nessa estação e na próxima, modelos de roupas e de acessórios que devem vestir em eventos de todo tipo, inclusive os do momento. Looks aprovados e reprovados em eventos como, por exemplo, o Oscar. Listas de compras e de roupas que não podem faltar em suas malas de viagem e assim por diante. Uma seção completa que instrui, orienta e conduz as adolescentes para se sentirem incluídas no mundo de hoje.

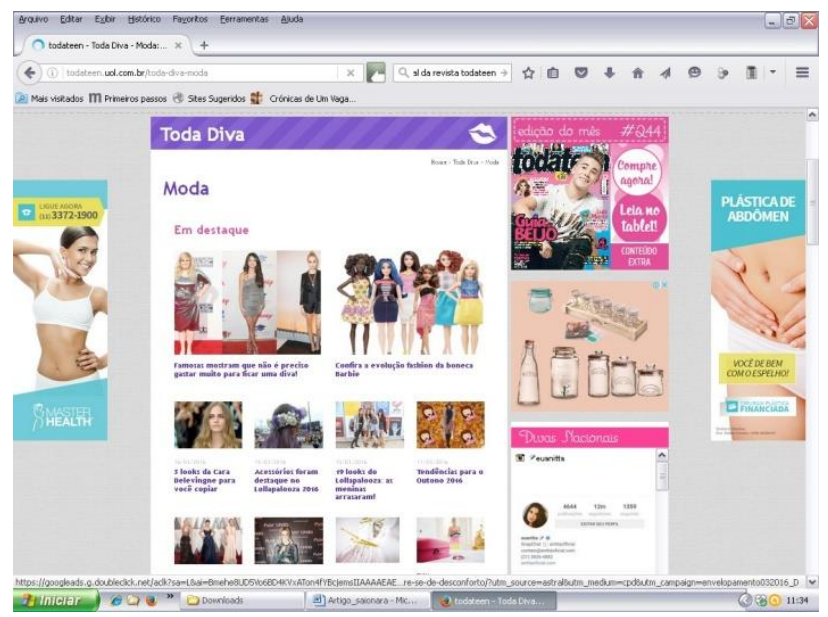

Figura 5 - A seção Toda Diva e uma das suas divisões "Moda" da Revista Todateen Fonte: Página da Revista Todateen na WEB ${ }^{9}$

e) Make (Fig. 6) - maquiagens e truques são apresentados nessa seção na promessa de corrigir imperfeições da pele, corrigir formatos de bocas, de olhos, de nariz e assim por diante num verdadeiro "cardápio" de opções para tornar a aparência como as leitoras julgam ser melhor para elas. Looks de celebridades para copiar e se sentir diva como essas celebridades são, cópias de maquiagem referentes à noite do Oscar, com passo-a-passo

\footnotetext{
${ }^{8}$ Disponível em http://todateen.uol.com.br/toda-diva-beleza> acesso em: março de 2016.

${ }^{9}$ Disponível em http://todateen.uol.com.br/toda-diva-moda> acesso em: março de 2016.
} 
para tornar a sua maquiagem igual a das artistas de cinema. Produtos para consumo são indicados na realização das maquiagens sugeridas na seção.

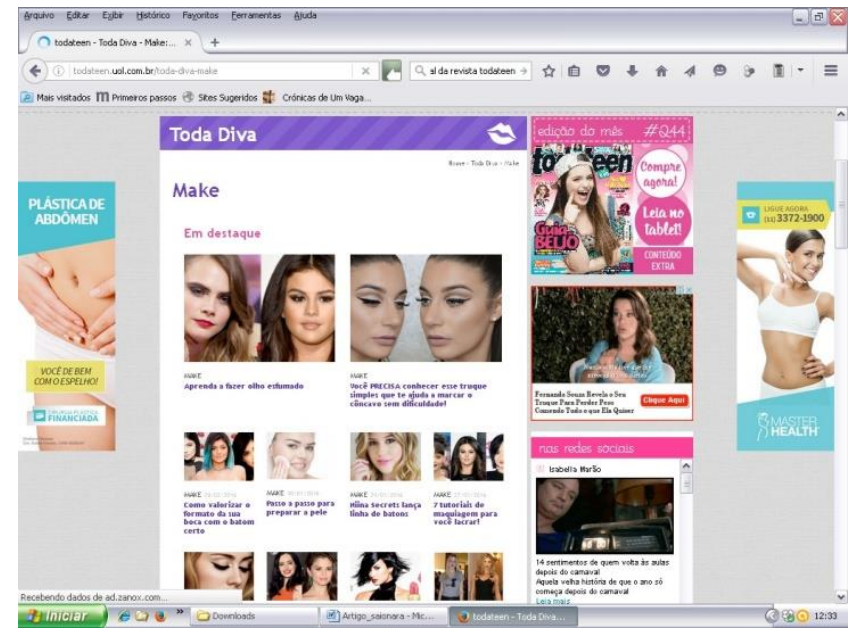

Figura 6 - A seção Toda Diva e uma das suas divisões "Make” da Revista Todateen Fonte: Página da Revista Todateen na WEB ${ }^{10}$.

f) Unhas (Fig. 7) - esse setor da revista destaca as unhas e as tendências do mundo atual para colocá-las em evidência, numa apresentação de tratamentos, dicas para deixar de roer as unhas, unhas de gel, unhas postiças, esmaltes e tudo o que a eles se refere - desde suas cores e tendências até seus usos específicos. Aqui também se aprende que cada festa ou evento do ano merece uma cor ou mais de uma cor nas unhas (carnaval, festas de halloween, casamentos, shows, etc.) da mesma maneira que as estações do ano também merecem destaque com tendências de como pintar as unhas e que cores devem ser usadas em cada estação. Coleções de esmaltes são lançadas a cada início de estação marcando bem os períodos e mais ainda as "tendências" que as leitoras devem seguir para serem atualizadas no quesito unhas.

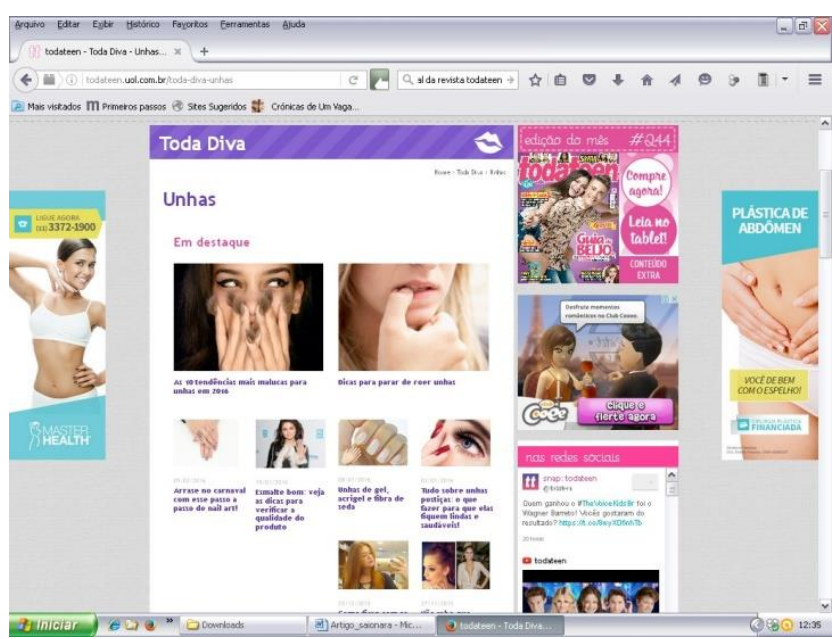

Figura 7 - A seção Toda Diva e uma das suas divisões "Unhas" da Revista Todateen Fonte: Página da Revista Todateen na WEB ${ }^{11}$.

${ }^{10}$ Disponível em http://todateen.uol.com.br/toda-diva-make> acesso em: março de 2016. 
Não se pode negar a variedade de temas da seção Toda Diva que a Revista Todateen oferece às suas leitoras. Cabe salientar que em cada uma das seções citadas nos itens acima, aparecem na página, mais embaixo, as alternativas "Em destaque", "Todas as matérias", "recomendamos para você" abrindo-se com isso um leque de oportunidades para ler e aprender sobre as coisas da atualidade numa linguagem acessível ao público ao qual a revista se destina de uma forma clara, bem didática ao mostrar muitas imagens coloridas ou vídeo explicativo sobre isso ou aquilo.

Além disso, na lateral à direita da revista aparece uma sugestão de produtos para serem comprados, outros produtos sendo oferecidos como amostras grátis, bastando requisitá-los como ensina a revista. Nesse mesmo setor à direita, ainda oferece cursos para que as leitoras aprendam a realizar o que leram na revista, seja para as unhas, cabelo ou qualquer outra parte do corpo que ela queira se aperfeiçoar. Há também uma parte destinada a mostrar o que de último acontece nas redes sociais, tornando seus leitores ou suas leitoras atualizadas em relação a tudo o que acontece com as celebridades, atualizando-os também nas diversas questões que se referem aos temas que agradem ao público adolescente.

Com uma simples pergunta e resposta: "Quer receber as dicas de beleza, moda e paquera da Todateen? Envie TEEN para 1315." a revista insere os seus leitores no "conteúdo mobile" desta forma tornando a revista mais um artefato a ser disponibilizado a qualquer hora e lugar pelos seus leitores por meio de seus aparelhos celulares. Assinando os canais de SMS da Todateen, os leitores passam a receber conteúdos exclusivos sobre moda, beleza, comportamento, gatos, horóscopo e muito mais ao custo de $\mathrm{R} \$ 3,99$ por mês.

Com a variedade de temas e de explicações não há como um(a) adolescente não aprender os modos de ser e de estar no mundo de hoje e se sentir parte dele, pois pelo que sugerem as dicas e normas expostas pela revista, não se atualiza quem não quer, não fica bonito(a) quem não quer, porque tudo aqui se ensina, inclusive os produtos a serem usados são sugeridos, com preços e promoções ao alcance de qualquer pessoa. É um convite a se atualizar diariamente, a imitar o seu ídolo e tudo o que ele(a) usa e assim as coloridas e atrativas páginas da WEB agem e interagem com seus(suas) leitores(as) num constante ensinar.

\section{Abre-se um parêntese para falar do corpo}

${ }^{11}$ Disponível em http://todateen.uol.com.br/toda-diva-unhas > acesso em: março de 2016. 
A Revista Todateen uma vez que se direciona ao público adolescente feminino e que no decorrer de sua seção "Toda Diva" imprime conceitos, formas e dita regras para subjetivar essas adolescentes, produzindo os modos de ser e de estar e também se referindo aos seus corpos, porque se sabe que um corpo é tudo o que nele se acopla, tudo o que se usa para se modificar a sua materialidade biológica, os acessórios que dele passam a fazer parte, as transformações que se realizam nele, sejam essas transformações permanentes ou não. O corpo é o protagonista quando se trata da maneira que eu quero ser e aparecer para os outros.

Goellner (2007) traz um conceito de corpo que vai além da anatomia física e sugere uma reflexão sobre as influências que acarretam a formação dos corpos, sua construção no tempo e na história e para isso as autoras se subsidiam de dois campos teóricos: Os estudos Culturais e a História do Corpo. Ambos possibilitam questionar saberes considerados pela teorização tradicional como verdadeiros, mas sem negar a materialidade biológica, porém não confere a essa materialidade a centralidade na definição do corpo em si.

As contribuições do campo teórico dos Estudos Culturais estão na desestabilização de verdades preconcebidas e no rompimento dos essencialismos; mais ainda das abordagens historicográficas críticas que através da ótica da medicina, estética, arte, nutrição, mídia, psicologia, lazer, moda, etc. têm tornado o corpo como o locus de investigação.

Para Goellner (2007), o corpo é provisório, mutável e mutante, suscetível a inúmeras intervenções, o corpo não é apenas um corpo, é também o seu entorno. Muito mais do que a anatomia, a parte biológica, o corpo também é a roupa, os acessórios, as intervenções que nele se operam, as máquinas que nele se incorporam, a educação de seus gestos. Assim, não são as semelhanças biológicas que o definem, mas os significados culturais e sociais que a ele se atribuem. O corpo é construído pela linguagem formando uma identidade

A produção cultural do corpo - mostra a contribuição de Michel Foucault em ambos os campos teóricos já citados, em que afirma que nossos gestos são construções culturais historicamente datadas e após analisar instituições como escolas, prisões, fábricas, hospitais ele fala do poder que investe no corpo diferentes disciplinas para conhecê-lo no detalhe, controlá-lo, docilizá-lo. Para Foucault, o controle da sociedade tem seu começo no corpo, com o corpo.

Em tempos atuais, a cultura que se produz é que o indivíduo é o responsável pelos cuidados de si, ele é o resultado de suas opções. É o responsável pelo seu corpo, saúde, 
beleza que tem ou deixa de ter. Aqui o exemplo de onde se opera a pedagogia cultural na revista em questão, Todateen, voltada para o público adolescente, mais especificamente feminino que incentiva a alimentação por meio de receitas sadias e naturais, exercícios milagrosos - pouco importando o dano causado para atingir um "bom resultado" - e uma promessa de vida saudável se seguir os conselhos dos profissionais que escrevem para a revista. Observa-se que a mídia influencia no nosso cotidiano com uma exigência corporal magra e saudável, destacando um padrão de corpo belo que não contempla a maioria das pessoas, que cada vez mais se angustiam ao se depararem frente a um cardápio imenso de opções para se alimentar, de conselhos a seguir e mais uma vez responsabilizando a pessoa por tudo o que lhe aconteça. Finalmente, diante de todas essas promessas, conselhos, frases imperativas de como comer, como vestir, como emagrecer, como ser belo, como não ser tão magro demais, como praticar atividades físicas encerram uma relação de poder, o poder de regular as condutas. O poder que mulheres, adultas e jovens devem exercer sobre si mesmas, num caprichoso cuidado diário que ao menor descuido pode desqualificá-la e desenquadrá-la dos padrões "normais" e aceitos pela sociedade.

\section{Todos querem ser vistos - "sou visto, logo existo"}

Nesse momento o trabalho enaltece a questão de que todas as pessoas hoje querem ser vistas, notadas. Assim a Revista Todateen proporciona às suas leitoras a oportunidade de aparecer na revista. Na seção "Batalha dos looks" (uma das divisões da seção Toda Diva) através de votos dos leitores da revista, a sua foto enviada pode ou não ser escolhida e assim a sua imagem, uma vez escolhida, aparecerá na próxima edição da Revista Todateen.

$\mathrm{Eu}$, tu, nós todos estamos conectados e querendo ser vistos na WEB. Com essa temática a antropóloga Paula Sibilia escreve no capítulo de título "Eu, eu, eu... você e todos nós" - do livro $O$ show do eu: a intimidade como espetáculo- em que faz uso da pergunta "como alguém se torna o que é?", usada por Nietzsche no subtítulo de sua autobiografia, obra essa que fez seus contemporâneos julgar traços de loucura tamanha a falta de modéstia e humildade usada para descrever-se, se achando o "tal".

Já hoje a megalomania e excentricidade não parecem desfrutar da mesma demonização, pois as pessoas expõem suas vidas privadas a qualquer momento na internet para dar conhecimento ao mundo de suas ações, assim como num diário, narram fatos cotidianos, mostram as mais diversas tarefas e horários que as realizam, seguem 
celebridades, consomem, informam-se e interagem em vários sites enfim exibem sua intimidade na internet. Esses comportamentos diante do que é exposto na WEB estão construindo as identidades do nosso mundo, do mundo contemporâneo.

A autora baseia-se em Nietzsche, em Foucault e em Deleuze, em dados numéricos e em publicações da mídia para nos mostrar que as pessoas comuns tornam-se personalidades do momento por minutos de fama num fenômeno conhecido como WEB 2.0, que acontece numa sociedade que cultiva o "ser diferente" ou "querer sempre mais". A rapidez que se converte em um mercado capaz de tudo devorar para convertê-lo em lixo, com isso grandes ambições e extrema modéstia aparecem de mãos dadas na promoção de você e eu que se espalha nos novos circuitos interativos: glorifica-se a menor das pequenezas, enquanto se parece buscar a maior das grandezas.

No século XXI, as "personalidades" são convocadas a se mostrarem. A privatização dos espaços públicos é a outra face de uma crescente publicidade do privado, um solavanco capaz de fazer tremer aquela diferenciação outrora fundamental. Em meio aos vertiginosos processos de globalização dos mercados em uma sociedade altamente midiatizada, fascinada pela incitação à visibilidade e pelo império das celebridades, percebe-se um deslocamento daquela subjetividade "interiorizada" em direção a novas formas de autoconstrução.

Paula Sibilia (2008) questiona como alguém se torna o que é? Diz que a internet tem ajudado bastante graças a um leque de práticas "confessionais" quer pessoas comuns como eu e você se apropriam para expor as suas rotinas de vida, configurando uma sociabilidade moderna, com algumas premissas básicas de autoconstrução e da tematização do eu. Dessa forma a rede mundial de computadores se tornou um grande laboratório, um ambiente propício para experimentar e criar novas subjetividades. Sem dúvidas, conclui a autora, que os espaços da WEB 2.0 são interessantes, nem que seja porque se apresentam como cenários bem adequados para montar um espetáculo cada vez mais estridente: o show do eu.

\section{As questões de gênero na Revista Todateen}

Duas revistas brasileiras foram problematizadas em trabalho realizado por SANTOS \& SILVA (2008): A Revista Todateen e a Revista Capricho. Conforme as autoras, ambas abordam ideais de relações entre gêneros que perpetuam o padrão tradicional dicotômico. As matérias prescrevem atitudes e comportamentos femininos que, 
apesar de parecerem diferentes e avançados, visam à manutenção de um padrão de gênero, no qual a iniciativa feminina nesta perspectiva envolve o "jeitinho feminino", isto é, ações indiretas de manipulação que podem dar ao rapaz a impressão de ter sido ele o idealizador da ação posta em prática. Esses dados parecem particularmente importantes quando pensamos em programas de saúde dirigidos a esse segmento populacional.

A respeito da dicotomia ao separar modelos de homens e de mulheres, a explicação a seguir faz um esclarecimento:

Os sujeitos que constituem a dicotomia não são, de fato, apenas homens e mulheres, mas homens e mulheres de várias classes, raças, religiões, idades, etc. e suas solidariedades e antagonismos podem provocar os arranjos mais diversos, perturbando a noção simplista e reduzida de "homem dominante versus mulher dominada". Por outro lado, não custa reafirmar que os grupos dominados são, muitas vezes, capazes de fazer dos espaços e das instâncias de opressão, lugares de resistência e de exercício de poder. (LOURO, 1997, p. 33)

Ainda conforme dados das autoras na análise das revistas há a valorização da heterossexualidade, de relacionamentos duradouros e monogâmicos, com a valorização do amor romântico para mulheres. As matérias conservam um padrão dicotômico de gênero, denotando uma polaridade que resulta numa relação complexa de jogos de posições, que conferem formas identitárias, sempre provisórias, de sentimentos, de pertinências ao gênero feminino ou masculino.

\begin{abstract}
Sujeitos masculinos ou femininos podem ser heterossexuais, homossexuais, bissexuais (e, ao mesmo tempo, eles também podem ser negros, brancos, ou índios, ricos ou pobres etc.). O que importa aqui considerar é que - tanto na dinâmica do gênero como na dinâmica da sexualidade - as identidades são sempre construídas, elas não são dadas ou acabadas num determinado momento. Não é possível fixar um momento - seja esse o nascimento, a adolescência, ou a maturidade que possa ser tomado como aquele em que a identidade sexual e/ou a identidade de gênero seja "assentada" ou estabelecida. As identidades estão sempre se constituindo, elas são instáveis e, portanto, passíveis de transformação. (LOURO, 1997, P.27)
\end{abstract}

Isso sugere que as identidades de gênero estão continuamente se transformando. Dessa forma, é indispensável admitir que até mesmo as teorias e as práticas feministas com suas críticas aos discursos sobre gênero e suas propostas de desconstrução - estão construindo gênero.

Como mostra esse trabalho a mídia ensina sobre gênero e essa pedagogia cultural opera por diversas ferramentas midiáticas como no caso, a Revista Todateen, desta forma essa abordagem quanto as subjetividades que a Revista pode construir na formação dos gêneros e suas implicações são importantes de se mencionar. Já que a seção que se baseia 
esse trabalho seja a que trata de ser "Toda Diva", seus conteúdos com dicas se voltam para a execução de benefícios às feminilidades do ser adolescente.

\section{Algumas considerações}

Para Silva (2002), pode-se dizer que através da perspectiva dos Estudos Culturais, a cultura passa a ser vista como uma pedagogia, e a pedagogia passa a ser vista como uma forma cultural. Esta afirmação corrobora para a compreensão da cultura como pedagogia e a pedagogia como cultura. Neste sentido, pode-se inferir que, outras instâncias culturais e processos extra-escolares, também são pedagógicos.

Mais do que um canal de comunicação entre leitoras, editoras e anunciantes, as revistas femininas juvenis de hoje se tornaram uma instância normativa de um determinado estilo de vida estruturado por meio do consumo de produtos e serviços e de um modo de pensamento e de construção de identidade.

Nota-se que a revista busca fazer mediação entre a ficção e a realidade, pretendendo influenciar a leitora a adotar "um certo" jeito de ser e de viver, um jeito de ser "toda teen", toda adolescente nas mais diversas formas de exercer isso. Encontra-se referências diversas sobre agentes da cultura de massa (que todo mundo pode fazer ou usar) que demonstram como este estilo pode ser vivido na "vida real". Neste sentido, observa-se na Todateen a presença de uma espécie de discurso normativo que prescreve o que é permitido ou proibido neste estilo de vida.

Para atingir seu objetivo a revista coloca-se diante da leitora como uma espécie de "melhor amiga", mais experiente ou simplesmente como uma desconhecida que "coincidentemente" está vivenciando questões semelhantes às vividas pela leitora. Ressalta-se neste tipo de publicação tanto a forma de linguagem coloquial utilizada pelos jornalistas e editores, quanto o uso do imperativo nas páginas analisadas. De alguma forma a leitura complementa "um ritual" de preparação para a convivência das adolescentes leitoras em seu grupo: na escola, nas festas, na família, etc.

Na Revista Todateen, a parte que serviu de estudo para a realização desse trabalho mostrou textos e imagens que de alguma forma ensinam, conduzem as leitoras a formar um pensamento, cabendo a ela fazer uso ou não para si das dicas, modelos, ideias, propostas, convites e sugestões da revista. A Revista ensina que as unhas devem ser tratadas, pintadas das cores da atualidade, os cabelos devem ser bem cuidados, se possível imitando cores e estilos de celebridades, a roupa e acessórios da moda devem ser adquiridos para que as adolescentes se sintam bem e por dentro da moda, o make diário também deve ser bem feito, pois uma boa maquiagem exclui qualquer defeito do rosto ou reproduz o semblante 
que se quer para o determinado evento. O corpo como um todo deve ser bem cuidado, de preferência um corpo magro, que segue dietas das mais variadas que se apresentam na mídia e como não poderia faltar a sugestão de práticas de atividades físicas que sugerem tornar o corpo sempre jovem e atraente a todos os olhares.

Diante desse manual de formas de ser e de estar apresentado pela Revista Todateen cabe ao público leitor decidir sobre si mesmo o quanto vai operar em sua vida as pedagogias exercidas por esse artefato cultural.

\section{Referências}

CAMOZZATO, Viviane Castro. Pedagogias do presente. Educação \& Realidade, Porto Alegre, v.39, n.2, abr/jun. 2014. p.573-593.

CAMOZZATO, Viviane Castro. Entre a pedagogia legisladora e as pedagogias intérpretes. Revista Brasileira de Educação, Campinas, São Paulo; v.21, n.61, 2015.

COSTA, Marisa Vorraber. Estudos Culturais: para além das fronteiras disciplinares. In:___ (Org.) Estudos Culturais em Educação: mídia, arquitetura, brinquedo, biologia, literatura, cinema. Porto Alegre: Editora da UFRGS, 2004.p. 13-36.

; ANDRADE, Paula Deporte. Na produtiva confluência entre educação e comunicação, as pedagogias culturais contemporâneas. In: $3^{\circ}$ RN ANPED, Goiânia, out. 2013. GT 16 "Educação e Comunicação".

; SILVEIRA, Rosa Hessel; SOMMER, Luis Henrique. Estudos Culturais, Educação e Pedagogia. Revista Brasileira de Educação. Número Especial - Cultura, Culturas e Educação. n. 23, p.26-61, maio/jun./jul./ago. 2003.

ESCOSTEGUY, Ana Carolina. Estudos Culturais: uma introdução. In: SILVA, Tomaz. O que é, afinal, Estudos Culturais. Belo Horizonte: Autêntica. 2004. p.133-166

GOELLNER, Silvana. A produção cultural do corpo. In: LOURO, GAUCIRA et al (Org.). Corpo, Gênero e Sexualidade: um debate contemporâneo na educação. 3 ed. Petrópolis: Vozes, 2007. p. 28-40.

LOURO, Guacira Lopes. Gênero, sexualidade e educação. Uma perspectiva pósestruturalista. Petrópolis, RJ : Vozes, 1997.

LARROSA, Jorge. Tecnologias do eu e educação. In: Silva, Tomaz Tadeu da (org). O sujeito da educação: estudos foucaultianos. Petrópolis: Vozes, 1994, p.35-86.

PARAÍSO, Marlucy Alves. Metodologias de pesquisas pós-críticas e educação e currículo: trajetórias, pressupostos, procedimentos e estratégias analíticas. In: MEYER, Dagmar Estermann; PARAÍSO, Marlucy Alves. Metodologias de pesquisas pós-críticas em educação. Belo Horizonte: Mazza Edições, 2012. p. 23-45. 
REVISTA TODATEEN. Disponível em: <http://www.todateen.uol.com.br> acesso em: mar. 2016.

SANTOS, Daniela Barsotti; SILVA, Rosalina Carvalho da. Sexualidade e normas de gênero em revistas para adolescentes brasileiros. Saúde Soc. vol.17 no.2 São Paulo Apr./June 2008.Disponível em:<

http://www.scielo.br/scielo.php?script=sci_arttext\&pid=S0104-12902008000200004> acesso em: 18 mar. 2016

SIBILIA, Paula. Eu, eu, eu...você e todos nós. In: O show do eu: a intimidade como espetáculo. Rio de Janeiro: Nova Fronteira, 2008. p. 7-28.

SILVA, Tomaz Tadeu. Documentos de Identidade: uma introdução às teorias do currículo. Belo Horizonte: Autêntica, 2002.

SODRE, Márcia Luiza Machado Figueira. Representações do corpo adolescente feminino na Revista Capricho: saúde, beleza e moda. (Dissertação de Mestrado) Programa de Pós- Graduação em Ciências do Movimento Humano. UFRGS, 2003. 
